\title{
Taxing unhealthy choices: The complex idea of liberal egalitarianism in health
}

\author{
Andreas Albertsen \\ Department of Political Science, Aarhus University \\ aba@ps.au.dk
}

This is a post print version. Published version located here

Albertsen, A. (2016). Taxing unhealthy choices: The complex idea of liberal egalitarianism in health. Health Policy, 120(5), 561-566. http://doi.org/10.1016/j.healthpol.2016.03.003

\begin{abstract}
Under the heading of liberal egalitarianism, Cappelen and Norheim present a novel approach regarding how we are to assess health disadvantages reflecting people's choices. It seeks to uphold a commitment to principles of responsibility and egalitarianism, while avoiding objections that such theories fail for humanitarian, liberal or fairness reasons. The approach draws a line between those of such diseases which are life-threatening, costly to treat relative to income or undermining important political capabilities and those which are not. For the latter kind, their approach allows for co-payment, whereas the former requires a different measure. Here, the authors maintain that unhealthy choices should be taxed and treatment offered equally to everyone without further cost. While this is an interesting approach, it faces important difficulties. It consists of two elements, which can come into tension with each other when concerns for severity of disease and personal responsibility recommend the employment of different elements. Furthermore, as it stands, the approach is incomplete because it seems unable to address important non-monetary shortages, such as the organ shortage. Finally, it isn't apparent how the approach is able to address the significant ways in which social circumstances influences people's choices in health and their ability to stay healthy.
\end{abstract}

Key Words: Health Equity; Social Inequalities; Distributive Justice; Personal Responsibility; Taxes on unhealthy behaviour; Social Determinants in Health; liberal egalitarianism; luck egalitarianism 


\section{Introduction}

Contemporary policy debates often emphasise the relationship between lifestyle and poor health outcomes, suggesting that this relationship may affect how we evaluate inequalities in health (1-3). This has brought forth the notion of personal responsibility, understood as the idea that we should give lower priority to those, who are deemed responsible for their own medical needs (1-17), and the developments of a series of attempts to introduce personal responsibility in health (18-24). But it has also spurred much criticism of such responsibility-sensitive approaches (17,25-34). Three objections have been very prominent. A humanitarian objection arguing that that responsibilitysensitive policies are too harsh on people, who are indeed responsible for their plight. A liberal objection pointing out how bad health can limit people fundamental political capabilities. A fairness objection which stresses that responsibility sensitive policies end up tolerating many influences on health which do not reflect people's exercises of responsibility. Explicitly acknowledging the strength of these objections Cappelen and Norheim have published two influential articles which explores and develops an interesting responsibility-sensitive approach $(35,36)$. Drawing on their two articles: 'Responsibility in health care: a liberal egalitarian approach', (35) and 'Responsibility, fairness and rationing in health care' (36), this article presents their liberal egalitarian approach and points to some difficulties and ambiguities within it. A central element in liberal egalitarianism is the idea of taxing unhealthy life-style choices with the purpose of providing treatment for free to those who fall ill from such choices. As such taxes are a frequent measure of raising revenue (37), discussing this policy measure and the reasons provided for it has broader interest.

\section{Material and Methods}

This section presents the liberal egalitarian approach based on the two articles and sets the scene for how it is to be evaluated. According to the authors liberal egalitarianism consists of two parts. A principle of responsibility, stating that people should be held accountable for their choices $(35,36)$ and a principle of equalisation, stating that individuals who make the same choices should also have the same outcome $(35,36) .{ }^{\mathrm{I}}$ In two articles they explore different aspects of what such a view may commit us to in relation to personal responsibility in health. In 'Responsibility, fairness and rationing in health care' they argue that there is a 'limited but significant role to personal responsibility' in decisions regarding diseases which reflect a person's exercise of responsibility,

\footnotetext{
I As an explicit source of these ideas, prominent responsibility-sensitive egalitarians are mentioned, such as Dworkin, Cohen, Arneson etc. (38-41)
} 
but are assumed to not have any of the impacts suggested by the three objections presented above (36). In 'Responsibility in health care: a liberal egalitarian approach' they propose an interpretation of the principle of responsibility, which allows for personal responsibility even when people could end up as badly as depicted by the humanitarian, liberal and fairness objection respectively. In the end we are offered two policy measures, each applicable to one of two sub-categories of diseases influenced or caused by people's choices $(35,36)$. One measure involves taxation of risky choices, while the other allows for out-of-pocket-payment for treatment of some diseases. II The liberal egalitarian approach allows for out-of-pocket payments for those diseases reflecting choices which are:

- Not life-threatening

- Not limiting the use of political rights or exercise of fundamental capabilities

- Inexpensive to treat compared to income (36).

Some diseases fulfilling those criteria will have been brought about completely or partly as a result of individual behaviour, while others result from factors outside the person's control. The authors argue that the optimal policy would be to charge actual cost co-payment for those who get such diseases through their own choice or negligence, with the purpose of offering full cover to those who get those diseases for reasons outside their control (36). The first element of Cappelen and Norheim's approach introduces co-payments for diseases related to individual choices which are not life-threatening, which do not limit political capabilities and where the cost of treatment is low in comparison with the patient's income. The next section examines the second element of the authors' approach.

By definition, the first element of Cappelen and Norheim's approach is silent regarding how we are to deal with diseases reflecting choices, which are in fact life-threatening, expensive to treat relative to income or diminish people's political capabilities. According to the authors, there is room for responsibility-sensitive policies even in such cases. As their second measure they propose that in such instances we should not hold people responsible for the consequences of their choices (the disease and associated costs), but rather for their risky choices $(35,36)$. As an institutional measure to this end they propose taxing potentially unhealthy activities to raise money for treating those who fall ill as a consequence of such choices. Each choice will be

II Unfortunately, the literature has done little to disentangle these two elements, often discussing only the former $(10,23,26,29,42,43)$. 
taxed the same, and nobody suffering from such diseases will be further charged for treatment. Instead, they are treated on equal terms with everyone else (35). This is the second element of the liberal egalitarian approach, which taxes potential unhealthy choices and provides treatment on equal terms for diseases related to individual choices which are life-threatening, which limits political capabilities or where the cost of treatment is high in comparison with the patient's income. The form of responsibility present in the second element of the approach can be understood as holding people responsible for their choices, as opposed to the consequences of their choices. This idea is proposed in both articles and in both instances it is highlighted how this avoids the bad consequences highlighted by the liberal and humanitarian objection $(35,36)$. The authors offer two reasons why we should introduce responsibility for choice rather than responsibility for costs for this category of disease. They will be presented below while also stressing how these reasons clearly reflect the author's ambition of presenting a theory which is not vulnerable to the humanitarian, liberal and fairness objections.

The first is that taxing unhealthy choices and treating those who fall sick due to the severe diseases in this category for free avoids potential harsh outcomes. It does not let people die from their diseases, or suffer severe economic hardship from medical bills or allow illness to diminish people's fundamental capabilities. All diseases in this category have, by definition, the potential to bring about such a scenario, but Cappelen and Norheim's proposal ensures that this does not transpire. In effect, this move seeks to steer clear of those bad outcomes envisioned by the humanitarian and liberal objections.

The authors offer a second reason, related to luck, for introducing a tax on unhealthy choices. The recurrent thought in the authors' text is that it is unfair if similar health choices lead to vastly different health outcomes. Such differences arise, due to the differential influence of luck, or as the authors sometimes describe it, factors outside the person's control. As examples of such factors, the authors submit 'different genetic makeup' and differences in luck, 'the parachute did not open' (35). But notably, this is two different kinds of luck. Recalling Dworkin's distinction between brute luck and option luck, where the latter is defined as 'a matter of how deliberate and calculated gambles turn out - whether someone gains or loses through accepting an isolated risk he or she should have anticipated and might have declined' (40). Brute luck is luck which does not have such deliberate or anticipated outcome. Genetic makeup is a clear-cut example of brute luck whereas the 
parachute seems an instance of option luck. In their argument for taxing unhealthy choices, the authors draw on a belief that both kinds of luck give rise to injustice. ${ }^{\text {III }}$ The unfairness, they argue, arises because the difference between the outcome of the persons' choices is due to luck (35). They submit that only in instances where people's health outcome 'depends solely on the individual's choices and not on any other factors that this principle implies that individuals should be held responsible for the consequences of their actions' ${ }^{\prime}(35)$. In effect this motivation mirrors the ambition of avoiding the objection regarding fairness.

In the following discussion, this approach to distributive justice in health will be evaluated in terms of coherence and completeness. The discussion tests whether the approach successfully combine a concern for those suffering from bad health outcomes with a notion of the prominent ideal of personal responsibility in health, and to what extent the concern is able to address important distributive questions, specifically non-monetary shortages (such as the organ shortage) and the complex relation between social circumstances and health outcomes.

\section{Discussion}

We now turn to a critical evaluation of the approach. Three criticisms will be raised in that regard. The first pertains to the coherence of the proposal, the second the completeness and the third its ability to address social inequalities in health and the insights from the social determinants in health literature.

\section{Coherence}

It is interesting to consider, whether there is coherence between the two elements in the approach and whether the reasons provided for them adequately support the proposed measures. Initially it is difficult to see how inner tensions could arise. After all, the measured are applied to two different kinds of health deficits. Surely, we may imagine practical difficulties deciding which diseases to consider as undermining important political capabilities and it could be discussed what it mean for the cost of treatment to be disproportional high in relation to a person's income. However, discussions of such practicalities are set aside by many approaches to health. Tensions arise because the authors oscillate between two distinctively different reasons for whether we are to introduce cost-responsibility or choice-responsibility. One set of reasons relate to how the disease came about, focussing on the presence or absence of luck (in the two meanings already specified). The other set

III Compensating both brute luck and option luck has recently been described as an all-luck egalitarian position $(23,44)$ 
of reasons has to do with the consequences the disease has for the person in question (while their approach talks of diseases which are life-threatening, this could also be broadened to include all severe health disadvantages). In their discussion of the diseases when cost-responsibility should be introduced, the authors provide a clear answer for where the distinction is drawn. Regarding lifethreatening diseases which are expensive to treat relative to income or undermining political capabilities, people should 'be held responsible for their choices not the consequences of their choices' (36). Clarifying with the now familiar interpretation that 'this argument supports levying taxes on tobacco instead of having lung cancer victims pay for their treatment'(36). There the authors provide a reference to the 2005 article and proceed to discuss how and why costresponsibility can be introduced for less serious diseases. When considering a disease reflecting people's choices, the liberal egalitarian approach have two distinct reasons why we may want to hold the person responsible for the choices rather than the consequences springing from these choices.

1) the disease is life-threatening, limiting political capabilities or expensive to treat compared to the person's income;

2) the disease reflects bad luck of a kind which should be redistributed.

The two considerations come apart in two situations. The first is when a person is solely responsible for being worse off in a way which makes him severely ill in a way that is included by 1) above. A crashed spare time Nascar driver might serve as an example. Here, considerations of severity of disease suggest that the person is to be held choice-responsible, while considerations of responsibility suggest that he is held cost-responsible. We could imagine a person arguing that although he is responsible for his plight, his bad health undermines his political capabilities, pointing out that shielding people from such fates where at heart of the liberal egalitarian approach. The second situation is when a person takes a health gamble and it turns out bad, but not bad enough regarding its life-threatening effects, expensiveness, or erosion of political capabilities to fall into the category of diseases, for which people should be held choice-responsible rather than cost-responsible. A person who is unlucky while parachuting ${ }^{\mathrm{IV}}$ and suffers a slight ankle sprain could illustrate such a case. Here, considerations of severity of disease suggest that he should be held cost-responsible, while considerations of responsibility suggest that he should be held choice-

Iv This is Cappelen and Norheim's example of compensable bad luck 
responsible. Imagine a person saying that although he isn't that badly off health wise, he is not responsible for his health outcome. This tension highlights that liberal egalitarians must seemingly make a choice. Either the presence of responsibility matters for all diseases, or it matters only for the diseases which are above the threshold established by the concern for whether a disease is deadly, expensive to treat or undermines political capabilities. In principle at least, either the authors must drop the reasoning that those who are solely responsible should be held costresponsible, or they must abandon the idea that all severely ill people can be offered treatment free of charge. This discussion shows that the authors' framework is seemingly further from succeeding in reconciling the concern for bad health outcomes with personal responsibility than it might have seemed at first.

\section{Non-monetary shortages}

A second but different kind of worry relates to whether the approach is able to cover the whole range of concerns we may have in the context of health. Both measures in the liberal egalitarian approach seek, under due considerations of fairness, to raise the money needed to provide treatment. This is done either through taxing unhealthy choices or allowing co-payment. But this gives rise to the question as to whether this is adequately able to achieve the liberal egalitarian ambitions across the sphere of health care. Interestingly, we face in this context a number of nonmonetary shortages. Roughly speaking, the term conveys the thought that for some diseases the primary reason why we cannot treat people free of charge is not that we cannot afford it in a monetary sense, but rather that there is another barrier. Consider the situation where there is a lack of sufficiently educated medical personnel as one example of a non-monetary shortage. But an even more prominent example shows more clearly, why such shortages are testing for the liberal egalitarian approach. Consider the question of allocating transplant livers among potential transplant recipients. Here we are clearly dealing with a life-threatening disease, and Cappelen and Norheim's approach would recommend taxing unhealthy behaviour (i.e. consumption of alcohol) and then offer treatment to everyone for free. However, raising extra funds does not make it possible to treat everyone. The money may eliminate the barrier associated with the cost of making an organ transplantation, but it does not provide us with the resource essential to the procedure. The most important barrier to achieve that goal is the organ shortage. Thus, Cappelen and Norheim's approach seems incomplete because it is unable to deal with cases where the shortage is not monetary. Such shortages are relevant because the underlying rationale behind taxing choices and providing equal treatment is that we raise the required resource through taxes and then avoid 
the concerns connected with denying treatment. But, when applied to situations where resources are scarce but the most important scarcity is non-monetary, the position turns up empty-handed. We cannot, at least not straightforwardly, increase the number of organs by charging people a tax for unhealthy behaviour which in the end may result in a need for a liver transplant. Therefore, an alcohol tax may pay the cost associated with a liver transplant but it will not as such make sure that there is a liver available for transplant. While this shortage may pose problems for many theories, it is highlighted here because it conflicts with at least some claims made in favour of liberal egalitarianism.

The liberal egalitarian might retort that people have, through taxes, been held responsible for their choices, and that treating them as equals need not imply that we cure everyone. It could just as well be taken mean that we tax unhealthy behaviour and treat everyone according to whatever (non-responsibility-sensitive) principle we deem appropriate. This strategy comes at some cost for the liberal egalitarian, because they must give up two attractive features of their theory. It is already noted that we cannot then uphold the idea that 'everyone who becomes sick is treated' (35). This would be true for many theories in a world of scarce resources, and it should be noted that at other times the authors prefer wordings similar to best available treatment (35). The suggested solution comes with another cost. That is that the liberal egalitarian then must allow the health choices of some to affect the treatment available to others. The idea of taxes was introduced with the purpose of shielding others from the costs associated with unhealthy choices. Claiming that the tax on alcohol consumption is sufficiently responsibility-sensitive would tolerate that the unhealthy choices of some reduces the chance of others receiving a liver transplant, due to the increased demand for livers. Importantly the above suggest that there may very well be an incompleteness in the liberal egalitarianism, where it is unable to fulfil the stated ambitions. Perhaps this calls for additional elements to be added for the approach to be able to say more in this regard.

\section{Social determinants in health: are all choices equal?}

The third concern to be discussed is that the liberal egalitarian approach may be too narrow, in the sense that it is not sufficiently attentive to the complex relation between social circumstance and health outcomes. This comes forth in two ways. Taxing every risky or potential unhealthy choice people make is a choice-sensitive policy, but it is only responsibility-sensitive insofar as people are considered responsible for every choice they make. Without going into larger metaphysical debates about competing accounts of responsibility, it is fair to say that this would amount to a controversial 
claim in the context of health. Not least because of the overwhelming evidence that some unhealthy choices, and the way in which such choices affect our health is contingent on our exposure to social determinants in health $(45,46)$. Taxing every choice which could be potentially unhealthy levies a tax on at least some choices for which people are not responsible. This is problematic because it disproportionately affects the worse off (47) and is in effect vulnerable to the concerns raised by the fairness objection. While the authors explicitly mention the concern for social influences on people's choices they do not explore or discuss, how to handle the possibility that some of the choices taxed by liberal egalitarianism are perhaps not choices people are responsible for.

But its apparent inability to deal with social influences on people's choices is not the only way in which the liberal egalitarian framework needs further development regarding social influences. Cappelen and Norheim submit that if people are not responsible for their condition, they should be treated free of charge. But discussing the distribution of medical resources is only a part of the equation. From the social determinants in health literature, we have learned that people's health is significantly influenced by where they live, whether they are employed and their general socio-economic position $(45,48)$. Should we then not take a broader interest than the liberal framework suggests? Should we not also be concerned with the fact that people's risk of falling ill is unequally distributed in the first place? The approach presented by Cappelen and Norheim addresses how to distribute medical resources within the healthcare system, applying either of the two elements of which their framework consists. But the liberal egalitarian focus on healthcare makes it perhaps to narrow. It thus seems unable to justify and recommend broader initiatives aimed at improving living conditions and the public health. Arguing that we should treat all smokers equally when they fall ill does not provide us reason to prevent people from smoking or help them quit the habit if they wish to do so. In the stated senses, the approach is too narrow, a way in which it seems weaker than other approaches, such as the luck egalitarian approach, which are readily equipped to deal with such social circumstances $(23,49)$. The above section suggests that the liberal egalitarian approach should be supplemented in ways that address and explore how social circumstances affects people's choices in health and the distribution of disease.

\section{Conclusions}

While an interesting approach, the liberal egalitarian approach offered by Cappelen and Norheim is underspecified and problematic in several ways. The above shows that there is a potential tension when concerns for severity of disease and influence from luck recommends the application of different elements. Furthermore, the approach is incomplete in that it seems unable to address important non-monetary shortages, 
such as the organ shortage. Finally, it isn't apparent how the approach is able to address the significant ways in which social circumstances influences people's choices in health and their ability to stay healthy.

\section{Acknowledgements}

This article was presented at the Annual Meeting in the Danish of Political Science Association in 2014. I am grateful for the comments received at that occasion from Esben Høgh, Søren Flinch Midtgaard, Anders Berg Sørensen and Jens Damgaard Thaysen. A significant part of the work on this article was made possible through support from The Carlsberg Foundation (grant number: CF14-0896). The funding source did not have a role in any of the following: study design, data collection, analysis, data collection, writing or decision to submit manuscript for publication.

\section{Literature}

1. Reiser SJ. Responsibility for personal health: a historical perspective. J Med Philos. 1985 Feb;10(1):7-17.

2. Leichter HM. "Evil Habits" and "Personal Choices": Assigning Responsibility for Health in the 20th Century. Milbank Q. 2003 Jan 1;81(4):603-26.

3. Minkler M. Personal Responsibility for Health? A Review of the Arguments and the Evidence at Century's End. Health Educ Behav. 1999 Feb 1;26(1):121-41.

4. Brown A. If We Value Individual Responsibility, Which Policies Should We Favour? J Appl Philos. 2005 Mar;22(1):23-44.

5. Bishop G, Brodkey AC. Personal Responsibility and Physician Responsibility - West Virginia’s Medicaid Plan. N Engl J Med. 2006 Aug 24;355(8):756-8.

6. Brown A. Personal responsibility: why it matters. London; New York: Continuum; 2009. 214 p.

7. Eyal N. Denial of Treatment to Obese Patients - the Wrong Policy on Personal Responsibility for Health. Int J Health Policy Manag. 2013;1(2):107-10.

8. Golan O. The right to treatment for self-inflicted conditions. J Med Ethics. 2010 Aug 16;36(11):683-6.

9. Le Grand J. Equity and choice an essay in economics and applied philosophy. London; ;New York, NY, USA : HarperCollins Academic,; 1991. 
10. Schmidt H. Bonuses as Incentives and Rewards for Health Responsibility: A Good Thing? J Med Philos. 2008 Jun 1;33(3):198-220.

11. Schmidt H. Personal responsibility in the NHS Constitution and the social determinants of health approach: competitive or complementary? Health Econ Policy Law. 2009 Mar 9;4(02):129.

12. Sharkey K, Gillam L. Should patients with self-inflicted illness receive lower priority in access to healthcare resources? Mapping out the debate. J Med Ethics. 2010 Nov;36(11):661-5.

13. van der Star SM, van den Berg B. Individual responsibility and health-risk behaviour: A contingent valuation study from the ex ante societal perspective. Health Policy. 2011 Aug;101(3):300-11.

14. Stell LK. Responsibility for Health Status. In: Rhodes R, Battin MP, Silvers A, editors. Medicine and social justice: essays on the distribution of health care. Oxford ; New York: Oxford University Press; 2002.

15. Tinghőg G, Carlsson P, Lyttkens CH. Individual responsibility for what? - A conceptual framework for exploring the suitability of private financing in a publicly funded health-care system. Health Econ Policy Law. 2010;5(02):201-23.

16. Ubel PA, Baron J, Asch DA. Social Acceptability, Personal Responsibility, and Prognosis in Public Judgments and Transplant Allocation. Bioethics. 1999 Jan;13(1):57-68.

17. Wikler D. Personal and Social Responsibility for Health. In: Anand S, Peter F, Sen A, editors. Public Health, Ethics, and Equity. Oxford; New York: Oxford University Press; 2004. p. 10935.

18. Albertsen A. Drinking in the last chance saloon: luck egalitarianism, alcohol consumption, and the organ transplant waiting list. Med Health Care Philos [Internet]. 2016 Feb 2 [cited 2016 Feb 5]; Available from: http://link.springer.com/10.1007/s11019-016-9684-7

19. Albertsen A. Tough Luck and Tough Choices: Applying Luck Egalitarianism to Oral Health. J Med Philos. 2015 Jun 1;40(3):342-62.

20. Albertsen A, Knight C. A framework for luck egalitarianism in health and healthcare. J Med Ethics. 2015 Feb 1;41(2):165-9.

21. Le Grand J. Individual responsibility, Health, and Health Care. In: Eyal N, Hurst S, Norheim OF, Wikler D, editors. Inequalities in health: concepts, measures, and ethics. Oxford: Oxford University Press; 2013. p. 299-306.

22. Segall S. In Solidarity with the Imprudent: A Defense of Luck Egalitarianism. Soc Theory Pract. 2007;33(2):177-98.

23. Segall S. Health, Luck, and Justice. Princeton, NJ: Princeton; 2010.

24. Voigt K. Appeals to Individual Responsibility for Health. Camb Q Healthc Ethics. 2013 Mar 14;22(02):146-58. 
25. Brown RCH. Moral responsibility for (un)healthy behaviour. J Med Ethics [Internet]. 2013 Jan 11 [cited 2013 Feb 24]; Available from: http://jme.bmj.com/cgi/doi/10.1136/medethics-2012100774

26. Buyx AM. Personal responsibility for health as a rationing criterion: why we don't like it and why maybe we should. J Med Ethics. 2008 Dec 1;34(12):871-4.

27. Buyx A, Prainsack B. Lifestyle-related diseases and individual responsibility through the prism of solidarity. Clin Ethics. 2012 Jul 19;7(2):79-85.

28. Daniels N. Individual and Social Responsibility for Health. In: Knight C, Stemplowska Z, editors. Responsibility and distributive justice. Oxford; New York: Oxford University Press; 2011. p. 266-86.

29. Feiring E. Lifestyle, responsibility and justice. J Med Ethics. 2008 Jan 1;34(1):33-6.

30. Fleck LM. Whoopie Pies, Supersized Fries. Camb Q Healthc Ethics. 2011 Dec 13;21(01):519.

31. Hausman DM. Egalitarian Critiques of Health Inequalities. In: Eyal N, Hurst S, Norheim OF, Wikler D, editors. Inequalities in health: concepts, measures, and ethics. Oxford: Oxford University Press; 2013. p. 95-112.

32. Nielsen L. Taking health needs seriously: against a luck egalitarian approach to justice in health. Med Health Care Philos. 2013 Aug;16(3):407-16.

33. Nielsen L, Axelsen DV. Three Strikes Out: Objections to Shlomi Segall's Luck Egalitarian Justice in Health. Ethical Perspect. 2012;19(II):307-16.

34. Venkatapuram S. Health justice. Cambridge: Polity Press; 2011.

35. Cappelen AW, Norheim OF. Responsibility in health care: a liberal egalitarian approach. J Med Ethics. 2005;31:476-80.

36. Cappelen AW, Norheim OF. Responsibility, fairness and rationing in health care. Health Policy. 2006;76(3):312-9.

37. Mossialos E, Le Grand J. Health care and cost containment in the European Union. Aldeshot ;;Brookfield [Vt.] USA: Ashgate; 1999.

38. Arneson RJ. Equality and equal opportunity for welfare. Philos Stud. 1989;56(1):77-93.

39. Cohen GA. On the currency of egalitarian justice. Ethics. 1989;99(4):906-44.

40. Dworkin R. What is Equality? Part 2: Equality of Resources. Philos Public Aff. 1981 Oct $1 ; 10(4): 283-345$.

41. Roemer JE. A pragmatic theory of responsibility for the egalitarian planner. Philos Public Aff. 1993;22(2):146-66. 
42. Schmidt H. Just health responsibility. J Med Ethics. 2009 Jan 1;35(1):21-6.

43. Vincent NA. What do you mean I should take responsibility for my own ill health? J Appl Ethics Philos. 2009;1(1):39-51.

44. Knight C. Egalitarian Justice and Expected Value. Ethical Theory Moral Pract. 2013 Feb 21;16(5):1061-73.

45. Marmot MG, Wilkinson RG. Social determinants of health. Oxford; New York: Oxford University Press; 2006.

46. Venkatapuram S, Marmot M. Epidemiology and Social Justice in Light of Social Determinants of Health Research. Bioethics. 2009 Feb;23(2):79-89.

47. Walker T. Why We Should Not Set a Minimum Price per Unit of Alcohol. Public Health Ethics. 2010 Jul 1;3(2):107-14.

48. Marmot MG. The health gap: the challenge of an unequal world. London: Bloomsbury; 2015. $387 \mathrm{p}$.

49. Albertsen A. Luck Egalitarianism, Social Determinants and Public Health Initiatives. Public Health Ethics. 2015 Apr 1;8(1):42-9. 